\title{
8
}
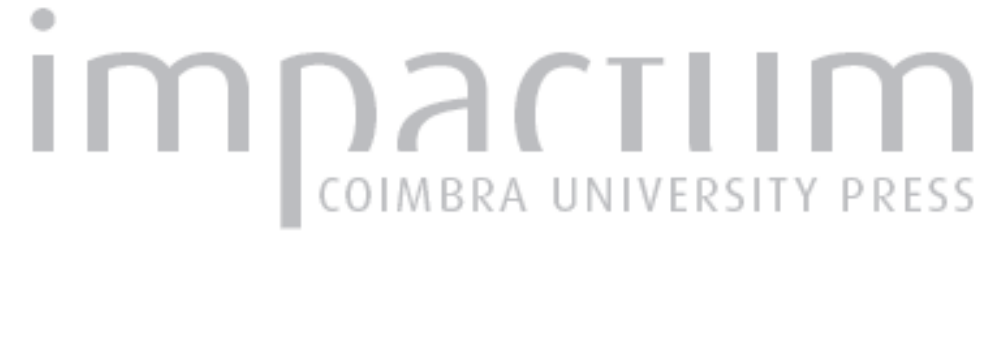

\section{Um ciclo iconográfico feminino na Idade do Ferro do Sul de Portugal}

Autor(es): $\quad$ Gomes, Francisco B.

Publicado por: Centro de História da Universidade de Lisboa

URL persistente:

URI:http://hdl.handle.net/10316.2/32979

DOI:

DOI:http://dx.doi.org/10.14195/0871-9527_22_6

Accessed : $\quad$ 26-Apr-2023 13:43:42

A navegação consulta e descarregamento dos títulos inseridos nas Bibliotecas Digitais UC Digitalis, UC Pombalina e UC Impactum, pressupõem a aceitação plena e sem reservas dos Termos e Condições de Uso destas Bibliotecas Digitais, disponíveis em https://digitalis.uc.pt/pt-pt/termos.

Conforme exposto nos referidos Termos e Condições de Uso, o descarregamento de títulos de acesso restrito requer uma licença válida de autorização devendo o utilizador aceder ao(s) documento(s) a partir de um endereço de IP da instituição detentora da supramencionada licença.

Ao utilizador é apenas permitido o descarregamento para uso pessoal, pelo que o emprego do(s) título(s) descarregado(s) para outro fim, designadamente comercial, carece de autorização do respetivo autor ou editor da obra.

Na medida em que todas as obras da UC Digitalis se encontram protegidas pelo Código do Direito de Autor e Direitos Conexos e demais legislação aplicável, toda a cópia, parcial ou total, deste documento, nos casos em que é legalmente admitida, deverá conter ou fazer-se acompanhar por este aviso.

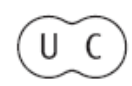



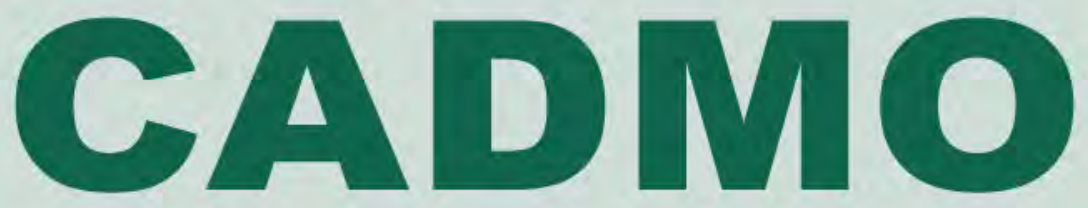

Revista de História Antiga

\author{
Centro de História \\ da Universidade de Lisboa
}

\title{
22
}

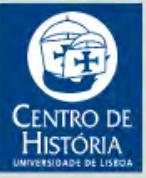

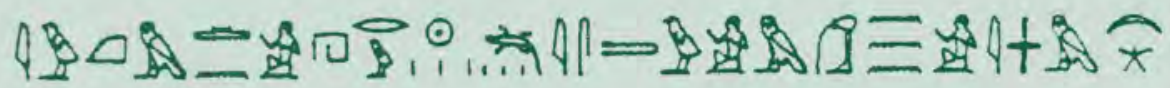

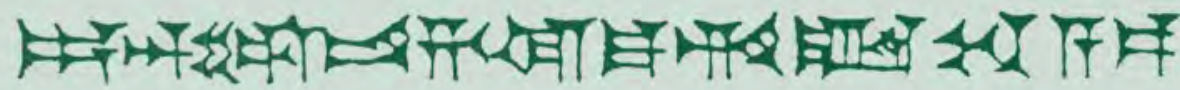
MHNIN AEI $\Delta \mathrm{E} \Theta \mathrm{EA} \Pi \mathrm{\Pi H} \Lambda \mathrm{HIA} \Delta \mathrm{E} \Omega$ 


\title{
UM CICLO ICONOGRÁFICO FEMININO NA IDADE DO FERRO DO SUL DE PORTUGAL
}

\author{
FRANCISCO B. GOMES \\ Universidade de Lisboa \\ franciscojbgomes@gmail.com
}

«What's in a name? That which we call a rose

By any other name would smell as sweet.»

W. Shakespeare, Romeo and Juliet, II, ii, 1-2

\section{Resumo}

Os elementos iconográficos de tradição mediterrânea não são demasiado abundantes na Idade do Ferro do Sul do actual território português, por oposição ao que sucede no vizinho território da Andaluzia Ocidental. Contudo, os dados actualmente disponíveis sugerem um claro predomínio de um ciclo iconográfico feminino, facto que poderá explicar-se pelas características do substrato religioso autóctone.

Palavras-chave: Orientalizante; iconografia; divindades femininas; Astarte/Tanit

\begin{abstract}
Iconographical elements of mediterranean tradition are not too common in southern Portugal's Iron Age, in contrast to the situation in the neighbouring territory of Western Andaluzia. Nonetheless, the data available today suggests a clear predominance of a feminine iconographical cycle, a situation that should possibly be explained by the character of the local religious background.
\end{abstract}

Key-words: Orientalizing; iconography; feminine divinities; Astarte/Tanit 
A iconografia de tradição mediterrânea presente em contextos da Idade do Ferro (grosso modo, séculos VIII-III a. C.) do Sul do actual território português permanece hoje, em grande medida, por valorizar; um trabalho de investigação que empreendemos recentemente ${ }^{33}$ e que esperamos poder publicar num futuro próximo, contudo, permitiu-nos entrever o grande potencial que esse material encerra para o conhecimento da estrutura ideológica e religiosa das comunidades sidéricas do território meridional português, bem como aferir a existência de certas regularidades que merecem ser assinaladas.

Dedicamos, por isso, o presente trabalho à exposição e discussão de uma dessas tendências gerais que pudemos observar no conjunto de materiais analisados: a existência de um conjunto muito substancial de testemunhos cuja leitura, directa ou indirecta, remete para a existência de um culto a divindades femininas particularmente disseminado.

Para esse efeito, apresentar-se-á em primeiro lugar um inventário com descrições abreviadas dos elementos que apresentam motivos iconológicos que reputamos conotáveis com o ciclo iconográfico cuja existência propomos, passando seguidamente à sua valorização de conjunto, naturalmente apoiada na abundante e riquíssima documentação proveniente do território da Andaluzia Ocidental, território cujo processo histórico no período em análise tem evidentes paralelismos com o Sul de Portugal.

\section{O corpus documental}

\subsection{Figuras femininas}

\subsubsection{Arrecadas do «Tesouro do Gaio», Sines (século VI a. C.)}

O chamado «Tesouro do Gaio», um conjunto funerário proveniente de uma sepultura aparentemente isolada, incluía um par de arrecadas áureas, em forma de crescente, com o corpo central oco, à qual se unem catorze pequenas cabeças femininas, bifrontes, encimando doze delas flores de lótus invertidas, abertas, caliciformes; a extremidade de cada uma destas arrecadas apresenta uma argola reforçada por fio de metal enrolado, em espiral, destinado à aplicação nas orelhas, que revelam, significativamente, desgaste. As peças foram unidas por soldagem, e a decoração apresentada foi obtida por estampagem e repuxado (AA.VV., 1996, p. 239). 


\subsubsection{Ex voto femininos do Castelo de Alcácer do Sal (final do século V a. C.-século IV a. C.)}

Entre o conjunto de trinta e dois ex votos antropomórficos e zoomórficos de bronze recentemente dados a conhecer por E. Gomes (2008) provenientes do importante povoado sidérico subjacente ao Castelo Medieval de Alcácer do Sal (cf. Silva et al., 1981; Arruda, 1999-2001: 64-72), e que parecem poder associar-se a um contexto de culto datável do final do século $\mathrm{V}$ a. C.-século IV a. C., estão presentes duas figuras de orantes claramente femininas (Gomes, 2008: peças 9 e 10), a que deverão acrescentar-se pelo menos mais duas figuras (idem, peças 38 e 39) de um conjunto que se encontra depositado na Biblioteca Nacional de Lisboa (BNL), classificadas pela autora como indeterminadas mas que apresentam, ao nível da indumentária, paralelos muito significativos com representações femininas presentes na abundante iconografia feminina da cerâmica pintada «ibérica».

A peça número 9 , incompleta apenas pela falta da perna direita, é uma peça de factura tosca, com os traços faciais rudemente representados, sendo apenas proeminente a figuração do nariz; os braços encontram-se erguidos; a perna conservada termina num apêndice pouco definido, representação do pé, sob o qual parece existir uma espécie de perne, que sugere que a peça se fixaria nalgum tipo de suporte; os seios da figura foram claramente figurados recorrendo a duas pastilhas aplicadas (idem: 64); a peça número 10, truncada por alturas do abdómen, encontra-se em pose semelhante à anterior; a expressão facial foi representada com um pouco mais de cuidado que a anterior, sendo de notar a boca aberta, com representação tosca da mandíbula, e os olhos, proeminentes; uma vez mais, aplicaram-se duas pastilhas como forma de representar explicitamente os seios (idem: 65). Ambas as figuras parecem ter sido figuradas nuas, tendo-se procurado enfatizar os seios, plausivelmente enquanto atributo sexual conotável com uma lógica de fertilidade e fecundidade.

Quanto às peças depositadas na BNL, a número 38 apresenta-se vestida com um chapéu ou gorro que confere à cabeça um aspecto globular; enverga ainda um manto ou túnica longo, cobrindo a totalidade do corpo, e sobre este uma capa curta, terminando pouco abaixo da cintura; um volume sobre o peito poderá representar o braço esquerdo, coberto pela capa; embora a autora sugira a existência de uma barba, as figuras publicadas não parecem confirmá-lo; a peça número 39 apresenta um característico gorro pontiagudo, ou um penteado alto coberto por um 
véu (idem: 85), cujos melhores paralelos se encontram em figurações femininas do mundo Ibérico (v., p. ex., Nicolini, 1969: 188-94); apresenta um manto longo, aberto à frente, de decote em $\mathrm{V}$, sob o qual parece envergar algum tipo de túnica de gola alta; os braços representam-se sobre tórax, o direito próximo do coração e o esquerdo um pouco mais abaixo (Gomes, op. e loc. cit.).

\subsubsection{Cabeças femininas bifrontes do castelo de Castro Marim ${ }^{34}$ (final do século IV- século III a. C.)}

O castelo de Castro Marim, amplamente intervencionado durante os anos '80 do século XX e novamente no início do presente século, revelou uma importante ocupação ao longo de toda a diacronia da Idade do Ferro, marcada por uma matriz cultural de claro aspecto mediterrâneo; de entre os numerosos aspectos do urbanismo que as longas intervenções permitiram identificar, destaca-se um edifício que, pela sua planta, pelas suas características arquitectónicas e por diversos aspectos do seu espólio pôde ser considerado como um espaço de culto (Arruda et al., 2009).

Entre o espólio exumado nesse espaço contam-se cinco pequenas cabeças femininas em pasta vítrea que, ao que tudo indica, formam pares, configurando assim figuras femininas bifrontes, embora de uma delas só se tenha recuperado uma face. No quadro seguinte sintetizam-se algumas das suas principais características:

\begin{tabular}{|l|l|l|l|l|}
\hline \multicolumn{1}{|c|}{$\mathbf{N}^{\circ}$. Inv. } & Alt. Máx. & Larg. Máx. & \multicolumn{1}{|c|}{ Esp. Máx. } & \multicolumn{1}{c|}{ Descrição } \\
\hline 3979 & $2,8 \mathrm{~cm}$ & $2 \mathrm{~cm}$ & $0,9 \mathrm{~cm}$ & $\begin{array}{l}\text { Penteado curto e possível gargan- } \\
\text { tilha; forma par com a peça 3978 }\end{array}$ \\
\hline 3978 & $2,2 \mathrm{~cm}$ & $1,8 \mathrm{~cm}$ & $0,9 \mathrm{~cm}$ & $\begin{array}{l}\text { Penteado curto, não conserva o } \\
\text { pescoço; forma par com a peça 3979 }\end{array}$ \\
\hline 3980 & $2 \mathrm{~cm}$ & $1,4 \mathrm{~cm}$ & $0,7 \mathrm{~cm}$ & $\begin{array}{l}\text { Penteado longo, egipcizante; forma } \\
\text { par com a peça 3977 }\end{array}$ \\
\hline 3977 & $1,9 \mathrm{~cm}$ & $1,3 \mathrm{~cm}$ & $0,7 \mathrm{~cm}$ & $\begin{array}{l}\text { Penteado longo, egipcizante; forma } \\
\text { par com a peça 3980 }\end{array}$ \\
\hline 3976 & $2,3 \mathrm{~cm}$ & $1,6 \mathrm{~cm}$ & $0,7 \mathrm{~cm}$ & Penteado longo, egipcizante \\
\hline
\end{tabular}




\subsubsection{Figurações femininas do depósito votivo de Garvão (final do século III a. C.).}

O interessante conjunto exumado nos anos '80 no Cerro do Castelo de Garvão que parece corresponder a um depósito votivo, plausivelmente um bothros ou favissa associado a algum contexto de culto próximo mas não identificado constituído num momento avançado do século III a. C. (Beirão et al., 1985: 46) inclui duas figuras femininas.

Uma pequena figurinha de argila com cerca de $15 \mathrm{~cm}$ de altura foi interpretada como representação feminina; trata-se de uma peça com um modelado frustre de aspecto algo geometrizante; a cabeça, toscamente modelada, apresenta orelhas, um nariz proeminente na continuidade da fronte, tendo os olhos sido representados pela adição de pequenas pastilhas de argila; em torno do pescoço parece ostentar um colar, originalmente formado por sete dessas pequenas pastilhas, de que se conservaram apenas três; também os seios foram representadas por esse método, mediante a aplicação de pastilhas de maiores dimensões, tendo-se conservado apenas a esquerda; conserva apenas o braço direito, que se encontra erguido em atitude de «bênção»; o braço esquerdo parece ter sido representado dobrado sobre o peito; a perna direita, quebrada acima do joelho, deveria apresentar-se adiantada, sugerindo movimento, ao passo que a perna esquerda, integralmente conservada e terminando num pé muito esquemático se manteria estática (idem: 82). Na opinião dos autores, tratar-se-ia de uma figura divina, facto testemunhado pela sua nudez, imprópria para a representação de um(a) devoto(a) (idem: 109), enumerando de resto numerosos paralelos para a peça em causa, nomeadamente no mundo púnico (idem: 110).

Duas placas de prata do mesmo contexto apresentam igualmente figurações femininas, interpretadas uma vez mais como representações da divindade cultuada no local, tendo-se igualmente enumerado numerosos paralelos relativos à iconografia da fenícia Astarte quer à da sua sucessora, a púnica Tanit (idem: 119-122). A primeira peça (idem: 89 e fig.34), uma placa subtrapezoidal, mede $53 \mathrm{~mm}$ de altura, $30 \mathrm{~mm}$ de largura máxima e aproximadamente $1 \mathrm{~mm}$ de espessura; na área distal, em posição centrada, figura uma cabeça antropomórfica, com 18×13 mm, realizada por repuxamento, ostentando sobre a fronte um toucado ou diadema; os olhos representam-se por dois pequenos pontos em relevo, e as arcadas supraciliares são bem vincadas; o nariz é largo, a boca pequena e linear; no que corresponderia ao peito da figura desenham-se duas linhas quase paralelas, plausivelmente 
representando um colar, quebradas na extremidade inferior onde, contudo, parecem ter suspendido um objecto subcircular. A segunda peça (idem: 91 e fig. 34), igualmente uma placa sub-trapezoidal, mede $44 \mathrm{~mm}, 21 \mathrm{~mm}$ de largura máxima e cerca de $0,5 \mathrm{~mm}$ de espessura; a toda a altura ostenta uma figura antropomórfica, de pé, realizada por repuxamento. A cabeça, com os olhos e a boca indicados, tem forma circular; o tronco representou-se por um arco de círculo enrolado nas pontas, em voluta, cujas extremidades correspondem aos mamilos; os braços, lineares, são representados erguidos à altura da cabeça, na designada posição de "orante»; as pernas e os pés representam-se por traços ondulados subparalelos. Na extremidade distal esta placa apresenta uma pequena perfuração circular.

Finalmente, este depósito continha igualmente um conjunto de treze placas, duas de ouro e onze de prata, com figurações de pares de olhos humanos realizados por repuxamento, representando com toda a probabilidade ex-votos de tipo anatómico, que deverão associar-se a alguma peculiaridade funcional, profiláctica, da divindade cultuada no santuário anexo (idem: 84-9 e figs. 31-3).

\subsubsection{Outras representações mal conhecidas}

Importa finalmente referir algumas referências passim e pouco desenvolvidas à existência de outras figurações femininas provenientes de contextos deste período:

- Uma terracota, aparentemente helenística, talvez correspondendo ao modelo dos chamados "queimadores em forma de cabeça feminina», da Necrópole do Olival do Senhor dos Mártires, em Alcácer do Sal (Correia, 1925: 166);

- Duas figuras femininas, sem outra descrição, que teriam sido recolhidas por Manuel Heleno no Castro da Azougada (Moura) (Beirão e Gomes, 1984).

\subsection{Representações de aves}

No território do Baixo Alentejo, nomeadamente na região de Ourique, conhecem-se desde os anos '80 numerosas necrópoles da ldade 
do Ferro, onde os influxos mediterrâneos se encontram plasmados de forma já bastante filtrada e indirecta, configurando o chamado mundo pós-orientalizante (Arruda, 2001). Recorrentes nos espólios destas necrópoles são as pequenas figuras ornitomórficas: da sepultura 2 do sector $B$ da Necrópole da Chada (Ourique), datada do século VI a. C., provêm dois pequenos ornitomorfos (Beirão, 1986: 98-102 e fig. 32), posteriormente identificados como pombas (Beirão e Gomes, 1984: 252); da necrópole do Cerro do Ouro (Ourique) provém uma peça, achada em decapagens superficiais, descrita como tampa uma vez que o corpo central é oco que figura uma ave de pescoço longo, curvado em «S", interpretável segundo C. M. Beirão e M. Varela Gomes como pertencendo ao género Cignus (Cisne), não havendo dados concretos para estabelecer a sua datação; finalmente, da necrópole de Corte Margarida (Aljustrel), de contextos funerários datados do século VI a. C., provêm outras duas peças representando, segundo os responsáveis da escavação, aves aquáticas, aparentemente patos, que parecem ter sido objecto de um tratamento cuidado (Deus e Correia, 2005: 617).

Da necrópole de Palhais (Beringel, Beja), recentemente intervencionada no âmbito de acções arqueológicas de salvamento no contexto da abertura dos canais de rega do Alqueva, provém igualmente um recipiente cerâmico, parte do espólio funerário da sepultura 3 (século VII a. C.), ostentando este motivo decorativo. Trata-se de uma taça de pé alto de fabrico manual com vestígios de pintura vermelha (motivos radiais?) em ambas as superfícies, sobre cujo bordo, simples, terão sido aplicados um número indeterminado de elementos coroplásticos decorativos figurando aves, embora muito esquemáticas, voltadas para o interior do recipiente (Santos et al., 2009: 772 e fig. 12). Outra peça do mesmo tipo foi também exumada em contextos de destruição de difícil datação, apresentando desta feita apenas dois ornitomorfos decorando também o bordo do recipiente (idem: 773 e fig. 15).

A este elenco poderia ainda acrescentar-se uma peça, referida apenas de passagem, proveniente do já citado depósito votivo de Garvão (final do século III a. C.): trata-se, segundo a descrição avançada pelos responsáveis da escavação, de uma peça do tipo designado «queimador» cujas pegas, diametralmente opostas e colocadas junto ao bordo, assumem a forma de aves; não está disponível qualquer descrição mais detalhada ou qualquer imagem da mesma (Beirão et al., 1985: 115). 


\subsection{Representações de felinos}

Finalmente, haveria a referir a existência de pelo menos três representações de felinos em contextos sidéricos. A mais bem conhecida provém de um contexto peculiar exumado na Rua do Rato, no casco antigo da vila de Alcácer do Sal, actualmente em processo de publicação. As características do espólio exumado nesta área sugerem a possibilidade de que aqui tenha existido um espaço de culto de feição ribeirinha, ligado à circulação fluvial, datável de finais do século VI-século V a. C. (Arruda et al., n.p.). Entre esse espólio conta-se um elemento cilíndrico oco, de bronze, figurando o prótomo de um felino, com cerca de $7,7 \mathrm{~cm}$ de comprimento por $4 \mathrm{~cm}$ de largura e $4,4 \mathrm{~cm}$ de altura (medidas máximas), produzido pela técnica da cera perdida, tendo-se figurado a pelagem no topo e na parte lateral da cabeça por incisão, provavelmente a cinzel. $\mathrm{Na}$ extremidade oposta ao prótomo do felino possui dois orifícios circulares para aplicação a um outro elemento. Um outro elemento em tudo semelhante a este provém do Castro da Azougada (Moura), tendo sido referido en passant por M. Varela Gomes (1983), que dele apresenta apenas uma fotografia pouco legível.

Da necrópole da Fonte Santa (Ourique), da I Idade do Ferro, provém uma peça cerâmica sem contexto seguro figurando um prótomo de carnívoro, plausivelmente de felino, em posição de ataque, com o pescoço longo erguido e um par de incisivos afiados; representam-se igualmente as narinas, os olhos obtidos pela aplicação de pastilhas de argila e as orelhas, hoje truncadas (Beirão, 1986: fig. 15; Beirão e Gomes, 1984: 451).

\section{Deusas, leões e aves: um ciclo iconográfico feminino}

A presença de um conjunto assinalável de figurações femininas na Idade do Ferro do Sul de Portugal ecoa a realidade global dos restantes territórios peninsulares marcados, de forma directa ou indirecta, pelos influxos culturais do Mediterrâneo Oriental. Esta omnipresença da figura feminina é com muita frequência associada ao culto de Astarte, a principal divindade feminina do panteão fenício no I milénio a. C. (Bonnet, 1996; Lipinski, 1995, pp. 128-154) ou, em fases mais tardias, coetâneas da expansão da influência de Cartago no Mediterrâneo Ocidental, com a hipotética expansão do culto de Tanit, enigmática figura que virá a tornar-se 
a mais popular e relevante deusa do panteão cartaginês (Fantar, 1998, pp. 252-262; Marín Ceballos, 1987).

No que diz respeito à primeira, o seu culto na Península Ibérica encontra-se bem atestado: uma inscrição fenícia na base de uma estatueta feminina provavelmente proveniente do santuário oriental de El Carambolo, próximo de Sevilha, é talvez o testemunho mais eloquente de que dispomos. O texto, conforme tradução recolhida por $\mathrm{C}$. Bonnet, é o seguinte:

Este trono foi feito por B'lytin, filho de D'mmlk, e 'bdb'l, filho de D'mmlk, filho de Yš'l, para Astarte hr, nossa senhora, porque ela ouviu a voz das suas palavras (Bonnet, op. cit., p. 127, adaptado).

Trata-se efectivamente de uma figura sedente, despida e com penteado egipcianizante, cujo trono infelizmente não foi recuperado. Encontra, por seu turno, paralelos em outras peças peninsulares que igualmente parecem representar a deusa oriental, nomeadamente: uma peça proveniente de Cádiz, representando uma figura feminina entronizada, desta feita envergando uma túnica, com um curioso mecanismo que permite erguer o braço da divindade (Marín Ceballos e Corzo Sánchez, 1991); a celebérrima «Dama de Galera», entronizada entre esfinges, ou uma outra figura, igualmente entronizada entre esfinges, com uma indumentária complexa, proveniente da necrópole de Puig dels Molins, em Ibiza (Blázquez, 2004). Estes elementos, a que se poderiam acrescentar outros mais (cf. Marín Ceballos, 1978; Bonnet, op. cit., pp.127-133), consubstancia uma efectiva presença daquela divindade oriental de complexa génese e personalidade na Península Ibérica durante o I milénio a. C. (Lipinski, op. et loc. cit.; Bonnet, op. cit., pp. 135-153).

No que aos testemunhos iconográficos do Sul do actual território português diz respeito, também eles parecem ecoar esta presença, embora não nos pareça lícito equacionar de forma directa as figurações surgidas em contextos autóctones com divindades de carácter exógeno quando, na ausência de fontes escritas, literárias ou epigráficas, não podemos descartar a adopção de iconografias alheias para divindades locais.

Não obstante, e nos casos específicos das peças de Castro Marim e da Herdade do Gaio, a semelhança é notória e a possibilidade, muito plausível, de se tratarem em ambos os casos de elementos de origem forânea, de importações, talvez permita sugerir, com relativa segurança, que estamos de facto ante figurações que, pelo menos na origem, se 
ligavam ao ciclo iconográfico de Astarte. Em ambos os casos estas figuras femininas são bifrontes, solução iconográfica atestada também, por exemplo, em peças áureas de Montemolín (Belén e Marín Ceballos, 2002, p. 176). As peças de Castro Marim, nomeadamente as de penteado longo, assemelham-se quer à já citada Astarte de El Carambolo quer às figuras de «mulheres à janela», tradicionalmente associadas a Astarte, frequentes nos famosos marfins de Nimrud (cf. p. ex. Bonnet, op. cit., pl. XI), em peças de Khorsabad (Winter, 2010, pp.3 00-2 e fig. 35) ou de Arslan Tash, a antiga Hadatu (idem, pp. 308-11 e fig. 36), estando estes últimos datados de forma relativamente segura de contextos do século VIII a. C. Todas as peças citadas são consideradas por I. Winter (idem) como exemplos de um «estilo» dentro da eborária do I milénio a. C. característico da Síria meridional.

A efectiva expansão do culto da cartaginesa Tanit, por seu turno, permanece ainda hoje um espinhoso problema, assente mais em interpretações de elementos cujo efectivo significado não se encontra provado do que em quaisquer provas substanciais (Marín Ceballos, 1987), do tipo daquelas de que dispomos para Astarte, divindade que se considera ter sido de certa forma «absorvida» pelo culto de Tanit, facto igualmente inteiramente por demonstrar de forma cabal.

A hipotética presença na necrópole do Olival do Senhor dos Mártires, em Alcácer, de uma terracota feminina de tipo helenístico, quer se ligue ao tipo dos «queimadores em forma de cabeça feminina» quer ao das figuras de tipo korotrophoi, tipos que têm sido associados ao culto de Tanit (idem), permanece por hora meramente especulativa, e até a peça ser re-identificada e devidamente estudada o seu real significado não pode ser aferido.

Por outro lado, as figuras femininas sobre placas de prata do depósito votivo de Garvão, pela sua cronologia tardia (plausivelmente do século III a. C., como acima se referiu) foram associadas a um hipotético culto de Tanit que teria lugar no santuário anexo. Aqui somos forçados a adoptar um tom de cepticismo, por várias razões: em primeiro lugar, o depósito de Garvão tem características muito peculiares ao nível da cultura material nele contida, que atesta para o putativo santuário associado um carácter supra-regional e plausivelmente supra-étnico (Fabião, 1998: 267-268), o que nos leva a manifestar as mais sérias reservas quanto ao culto de uma divindade forânea por si mesma; em segundo lugar, ainda que pudéssemos admitir um carácter forâneo para a divindade cultuada em 
Garvão, não se nota quer no depósito quer, de forma significativa, na região, um influxo cultural cartaginês suficientemente vigoroso que justifique a presença de uma divindade do panteão norte africano; se aceitássemos como premissa a presença de uma divindade forânea seria mais provável associar o hipotético santuário de Garvão a Astarte.

Igualmente bem atestadas, como vimos, estão as representações de felinos, presentes quer em contextos associáveis a santuários (caso das peças de Alcácer e da Azougada) quer funerários (a peça da Fonte Santa). O seu significado é particularmente críptico, mas algumas chaves de interpretação se podem invocar, provenientes quer do mundo próximooriental quer do mundo do Levante peninsular, dito «ibérico».

De facto, em artigo recente M. Belén e M. C. Marín Ceballos traçam a propósito de algumas peças peninsulares um interessante quadro da associação das figuras felinas a divindades femininas, numa longa linhagem que remonta à mesopotâmica Inanna/Istar e inclui a fenícia Astarte, excelente trabalho para o qual remetemos (Belén e Marín Ceballos, 2002). Aí assinalam uma impressão que nós próprios já tínhamos verificado em relação às peças do nosso inventário: a identificarem-se os felinos representados nestas peças como leões (Panthera leo), como tradicionalmente se admite para os felinos próximo-orientais que surgem tão frequentemente associados ou simbolizando as divindades femininas referidas, será mais correcto identificá-los como fêmeas, como leoas (idem, pp. 175-6) (a ausência de juba nas peças que tivemos oportunidade de inventariar assim o sugere).

Por outro lado, na iconografia dita «ibérica», surge recorrentemente uma figura, tradicionalmente designada como carnassier, "carnívoro», representada na bronzística, na escultura e na pintura vascular (González Alcalde e Chapa Brunet, 1993). Esta figura, interpretada como representando um lobo, foi considerada como desempenhando um papel iconológico grosso modo equivalente ao do leão noutros contextos. C. de Mello Beirão e M. Varela Gomes (1984, p. 468) associam a peça coroplástica da necrópole da Fonte Santa a este motivo iconográfico, leitura que Ihes é em parte permitida pelo aspecto tosco da peça. Julgamos, não obstante, que na ausência de outros elementos representativos da iconografia do lobo no Ocidente peninsular será mais provável que a peça da Fonte Santa represente um leão, ou mais exactamente uma leoa.

A interpretação destas peças dentro de um ciclo conectado com as figuras femininas comentadas acima, ecoando as divindades orientais cuja 
iconografia estará provavelmente na origem da representada nas peças em apreço, cujo carácter simultaneamente maternal, sensual e aguerrido encontra uma representação privilegiada na leoa, é uma possibilidade verosímil, mas longe de estar taxativamente demonstrada. O que, por seu turno, parece certo, é que à semelhança da figura do carnassier Ibérico (González Alcalde e Chapa Brunet, op. cit., pp. 170-2), o leão assume no contexto geográfico sobre o qual incide este estudo uma cariz simultaneamente cultual e funerário, atestado pelos contextos das peças inventariadas.

Finalmente, são também numerosas as figurações ornitomorfas, quer de aves que podem, putativamente, ser interpretadas como pombas quer, por outro lado, de aves aquáticas (cisnes e patos?). Estas parecem concentrar-se nas necrópoles sidéricas do Baixo Alentejo (Chada, Cerro do Ouro, Corte Margarida), embora haja igualmente referência a uma peça coroplástica decorada com aves do bothros de Garvão.

As aves são sobejamente conhecidas na iconografia peninsular de origem mediterrânea, estando representadas na pintura vascular, na bronzística e na coroplástica, virtualmente sempre associadas à divindade feminina, quer esta se interprete como Astarte, Tanit ou como divindade do âmbito grego (Prados Torreiras, 2004, pp. 100-102).

A este propósito enunciaremos apenas alguns dos mais ilustrativos exemplos peninsulares dessa associação: oriundo provavelmente do santuário de El Carambolo, próximo de Sevilha, o chamado Bronze Carriazo (Jiménez Ávila, 2002, p. 411) figura uma divindade feminina (a confirmar-se uma origem naquele santuário, tratar-se-á sem dúvida de Astarte, cujo culto está aí epigraficamente atestado [cf. supra]) com um penteado dito "hatórico», característico da iconografia de Astarte, ladeada por dois prótomos de aves, configurando uma espécie de barca solar (Prados Torreiras, op. cit., p. 96); do santuário de Collado de los Jardines (Jaén) procedem dois ex votos de bronze, ambos femininos, um em pose de orante e outro de ofertante, ambos segurando uma ave (pomba?) numa das mãos (idem, fig. 4); do povoado de La Quéjola (Albacete) provém um excepcional thymiaterion de bronze, cujo prato é suportado por uma figura feminina, nua, segurando nas duas mãos unidas uma ave (pomba?) (idem, fig. 15). Finalmente, referiríamos a celebérrima "dama de Baza», figura luxuosamente vestida e entronizada, frequentemente associada a Astarte, que segura nas mãos, uma vez mais, uma ave (pomba?). 
O trabalho de Maria. L. Prados Torreiras (op. cit.) é, para o efeito da análise do nosso inventário, interessante ao desenvolver uma interpretação para estas figurações de aves que as associa a um ideal de fertilidade e vitalidade que, não obstante, surgiria associado a concepções escatológicas, do Além (idem, p. 102). Também na nossa área de estudo as pequenas aves surgem sobretudo em contexto funerário, sugerindo-nos que teriam, pelo menos na área cultural que abrange a actual região do Baixo Alentejo, um significado escatológico.

\section{Discussão e reflexões finais}

As reflexões tecidas nos pontos anteriores confirmam uma tendência existente dentro do conjunto dos materiais iconográficos sidéricos do Sul do actual território português para a adopção de motivos iconológicos conectados com uma divindade feminina, que consubstanciará sem dúvida as características da estrutura religiosa das populações que, durante 0 largo período da Idade do Ferro, ocuparam a parcela meridional do actual território nacional.

De facto, quando se conhece a sua proveniência, os elementos referenciados provêm na sua vasta maioria de contextos com uma clara conotação ritual - santuários, depósitos votivos ou contextos funerários -, pelo que podemos com confiança extrair algumas ilações quanto à natureza da religiosidade das sociedades em estudo a partir destes materiais.

Não nos inclinamos, como alguns autores, a assumir que esta tendência que assinalámos decorre de um simples processo de aculturação, em que as populações autóctones adoptam a estrutura religiosa dos comerciantes e colonos orientais (Marín Ceballos, 1978); as bem fundamentadas e lúcidas críticas a este modelo tecidas por $\mathrm{C}$. Wagner (1986) e J. Alvar (1990) são, neste ponto, referências obrigatórias. O contexto dos materiais analisados, contudo, não suporta também a tese, defendida pelo primeiro daqueles autores (Wagner, 1986: 141-2), de que os materiais iconográficos deste tipo chegariam aos contextos autóctones como meros elementos de prestígio, despidos já de todo o seu significado religioso e ideológico.

Os dados que manejamos, embora escassos, sugerem claramente a adopção de iconografias mediterrâneas para cultos cujos moldes são 
difíceis de estabelecer, mas que parecem amplamente influídos pelos contactos com o Mediterrâneo. Conhecemos mal as características do substrato religioso do Bronze Final do Sudoeste, facto que condiciona enormemente qualquer tentativa de leitura diacrónica, mas julgamos que os dados apresentados são muito sugestivos na hora de propor a existência de cultos de fertilidade e fecundidade em torno de uma divindade feminina, com uma vitalidade evidente, que condicionam a adopção diferenciada de elementos iconográficos forâneos bem como o desenvolvimento da religiosidade local na Idade do Ferro.

Que se tenha prestado culto de forma mais ou menos directa a Astarte em pólos como Castro Marim ou o núcleo populacional a que corresponderá a Necrópole do Gaio não parece demasiado descabido à luz do importante influxo oriental que aí se verifica (cf. Arruda, 1999-2000; 2005). O que propomos relativamente aos restantes contextos é que se tenha dado uma identificação, uma interpretatio, de uma divindade local, de carácter nutrício, salutífero e putativamente também psicopompo, a julgar pela sua presença em contextos funerários, com aquela divindade próximo-oriental. O carácter poliédrico de Astarte tem sido sistematicamente sublinhado, e é de facto impressionante a forma como esta divindade foi assimilada a numerosas divindades de vários contextos culturais na bacia do Mediterrâneo (Grottanelli, 1981: 120-121). Se em Garvão, no Castro da Azougada ou no interior alentejano se conhecia, nesta época, o nome de Astarte (ou de Tanit) é algo que talvez nunca venhamos a saber. Mas o seu carácter e a sua iconografia parecem ter sido plenamente identificados com o perfil de uma divindade indígena cujo culto e devoção se encontram profundamente arreigados.

A imagem, truncada mas ainda assim coerente, de que dispomos para a Idade do Ferro, é neste momento a melhor via de que dispomos para abordar a religiosidade das populações autóctones que servem de interlocutoras dos comerciantes orientais. Não pretendemos, de forma alguma, subestimar a complexidade do tecido étnico e cultural abrangido pelas manifestações iconográficas que enumerámos; estas distribuem-se por um território amplo, onde os influxos mediterrâneos chegam em graus e modos diferenciados, e por uma cronologia longa, que ultrapassa meio milénio.

Não obstante, parece defensável que a existência de uma divindade feminina com o perfil acima traçado tenha recebido um culto em maior ou menor grau transversal, não obstante os matizes (sub-)regionais e locais que terão, sem dúvida, existido, e que por hora nos escapam. Este dado permite-nos entrever a hipótese, muito sugestiva, de que o culto a essa 
divindade, rapidamente associada à fenícia Astarte, se tenha instituído como um dos pilares ideológicos das relações com os comerciantes e eventuais colonos oriundos do Mediterrâneo Oriental.

\section{Notas}

(1) Estudo realizado no âmbito do seminário "Arte Pré-Clássica», orientado pelo Professor Doutor Luís de Manuel Araújo, a quem gostaria de expressar o meu agradecimento pela disponibilidade no acompanhamento do mesmo.

(2) Devo à amabilidade da Professora Doutora Ana Margarida Arruda, que dirigiu as intervenções arqueológicas no castelo de Castro Marim, toda a informação sobre estas peças, facto pelo qual expresso a minha gratidão.

\section{Bibliografia}

AA.VV. (1996), De Ulisses a Viriato: o I milénio a.C. Lisboa: MNA

J. ALVAR (1990), La religión como índice de aculturación: el caso de Tartessos. Atti del Il Congreso Internazionale di Studi Fenici e Punici, I, pp. 351-6. Roma: CNR

A. M. ARRUDA (1999-2000), Los Fenicios en Portugal. Fenicios y mundo indígena en el centro y sur de Portugal (siglos VIII-VI a.C.). Cuadernos de Arqueología Mediterránea, Vol. 5-6. Barcelona: Laboratorio de Arqueología de la Universidad Pompeu Fabra.

A. M. ARRUDA (2001), A Idade do Ferro Pós-Orientalizante no Baixo Alentejo. Revista Portuguesa de Arqueologia, 4:2, pp. 207-291. Lisboa: IPA

A. M. ARRUDA, P. A. CARRETERO POBLETE, V. T. de FREITAS, E. de SOUSA, P. BARGÃO, P. LOURENÇO, C. F. OLIVEIRA (2009), Castro Marim: un santuário en la desembocadura del Guadiana. In: P. Mateos Cruz, S. Celestino Pérez (eds.), Santuarios, oppida y ciudades: arquitectura sacra en el origen y desarrollo urbano del Mediterráneo Occidental, pp. 79-88. Madrid: CSIC

A. M. ARRUDA, M. FERREIRA, E. de SOUSA, P. LOURENÇO, J. LIMA, A. C. CARVALHO (no prelo), Contributos para o conhecimento da Idade do Ferro de Alcácer do Sal: os dados da Rua do Rato.

C. de M. BEIRÃO (1986), Une Civilisation Protohistorique du Sud du Portugal (ler Âge du Fer). Paris: Éditions du Boccard

C. de M. BEIRÃO, M. V. GOMES (1984), Coroplastia da I Idade do Ferro do Sul de Portugal. In: Volume d'Hommage au géologue Georges Zbyzewsky, pp. 450-482. Paris: Ed. Recherches sur les civilisations

C. M. BEIRÃO, C. T. da SILVA, J. SOARES, M. V. GOMES, R. V. GOMES (1985), Depósito votivo da Il Idade do Ferro de Garvão. Notícia da primeira campanha de escavações, O Arqueólogo Português, série IV, 3, pp. 45-135. Lisboa: Museu Nacional de Arqueologia e Etnologia

M. ${ }^{a}$ BELÉN, M. C. MARÍN CEBALLOS (2002), Diosas y leones en el período orientalizante de la Península Ibérica. SPAL, 11, pp. 169-196. Sevilha: Secretariado de Publicaciones de la Universidad de Sevilla

J. M. ${ }^{a}$ BLÁZQUEZ MARTíNEZ (2004), Astarte entronizada entre esfinges de Puig dels Molins, Ibiza», In: Actas del III Congreso Español de Antiguo Oriente Próximo, Huelva Arqueológica, 20, pp. 115-125. Huelva: Diputación Provincial de Huelva 
C. BONNET (1996), Astarte. Dossier documentaire et perspectives historiques. Roma: CNR

V. CORREIA (1925), Uma conferência sobre a Necrópole de Alcácer do Sal. Biblos 1:7, pp.347363. Coimbra: Faculdade de Letras da Universidade de Coimbra

M. DEUS, J. CORREIA (2005), Corte Margarida. Mais uma Necrópole Orientalizante no Baixo Alentejo. In J. Jiménez Ávila, S. Celestino Pérez (eds.), El Período Orientalizante, pp. 615-618. Madrid: CSIC

M. H. FANTAR (1998), Carthage. Approche d'une Civilisation. Tome 2. Tunis: Alif

E. GOMES (2008), Os ex-votos proto-históricos do Castelo de Alcácer do Sal. Dissertação de mestrado em Arqueologia apresentada à Faculdade de Letras da Universidade de Lisboa. Edição policopiada, 2 volumes.

M. V. GOMES (1983), El «smiting god» de Azougada (Moura). Trabajos de Prehistoria, 40, pp. 199-220. Madrid: CSIC

J. GONZÁLEZ ALCALDE, T. CHAPA BRUNET (1993), «Meterse en la boca del lobo». Una aproximación a la figura del «carnassier» en la religión ibérica. Complutum, 4, pp. 169-174. Madrid: Servicio de Publicaciones de la Universidad Complutense de Madrid.

C. GROTTANELLI (1981), Santuari e divinità delle colonie d'Occidente. In: La religione fenicia: matrici orientali e sviluppi occidentali, pp. 109-133. Roma: CNR.

J. JIMÉNEZ ÁVILA (2002), La toréutica orientalizante en la Península Ibérica. Madrid: Real Academia de la Historia.

E. LIPINSKI (1995), Dieux et Déesses de l'Univers Phénicien et Punique. Leuven: Peeters.

M. C. MARÍN CEBALLOS (1978), Documents pour l'étude de la religion phénico-punique dans la Péninsule Ibérique. Astarte. Actes du Deuxième Congrès International d'étude des Cultures de la Mediterranée Occidentale, pp.21-32. Alger: Université d'Alger.

M. C. MARÍN CEBALLOS (1987), Tanit en España?, Lucentum, 6, pp. 43-80. Alicante: Universidad de Alicante.

M. C. MARÍN CEBALLOS, R. CORZO SÁNCHEZ (1991), Escultura feminina entronizada de la necrópolis de Cádiz. Atti del II Congresso Internazionale di Studi Fenici e Punici, vol. 3, pp. 1025-1038. Roma: CNRS.

G. NICOLINI (1969), Les bronzes figurés des sanctuaires ibériques. Paris: Presses Universitaires de France.

M. ${ }^{a}$ L. PRADOS TORREIRA (2004), Un viaje seguro: las representaciones de pies y aves en la iconografía de época ibérica. Cuadernos de Prehistoria y Arqueología de la Universidad Autónoma de Madrid, 30, pp. 91-104. Madrid: Universidad Autónoma de Madrid.

F. SANTOS, A. S. ANTUNES, C. GRILO, M. DEUS (2009), A Necrópole da I Idade do Ferro de Palhais (Beringel, Beja). Resultados preliminares de uma intervenção de emergência no Baixo Alentejo. IV Encuentro de Arqueología del Suroeste Peninsular, pp. 746-804. Huelva: Secretariado de Publicaciones de la Universidad de Huelva.

C. T. da SILVA, J. SOARES, C. de M. BEIRÃO, L. F. DIAS, A. COELHO-SOARES (1980-1981), Escavações arqueológicas no Castelo de Alcácer do Sal (campanha de 1979). Setúbal Arqueológica, 6-7, pp. 149-218. Setúbal: MAEDS.

C. WAGNER (1986), Notas en torno a la aculturación en Tartesos. Gerión, 4, pp. 129-160. Madrid: Secretariado de Publicaciones de la Universidad Complutense.

I. WINTER (2010), On Art in the Ancient Near East. Volume I, Of the First Millenium BCE. Boston: Brill. 